\title{
Risk Assessment of Agricultural Drought Disaster on the Huaibei Plain of China Based on the Improved Connection Number and Entropy Information Diffusion Method
}

\author{
Menglu Chen ${ }^{1}$, Shaowei Ning ${ }^{1,2, *}$, Juliang Jin ${ }^{1}$, Yi Cui ${ }^{1,3}$, Chengguo $\mathrm{Wu}^{1}$ and Yuliang Zhou ${ }^{1} \mathbb{D}$ \\ 1 School of Civil Engineering, Hefei University of Technology, Hefei 230009, China; \\ chenmenglu901127@sina.com (M.C.); jinj166@126.com (J.J.); cuiyi9007@163.com (Y.C.); \\ wucguo@outlook.com (C.W.); ZYL54600@163.com (Y.Z.) \\ 2 Department of Civil and Earth Resources Engineering, Kyoto University, Kyoto 615-8540, Japan \\ 3 State Key Laboratory of Hydraulic Engineering Simulation and Safety, Tianjin University, \\ Tianjin 300072, China \\ * Correspondence: ning@hfut.edu.cn
}

Received: 23 February 2020; Accepted: 9 April 2020; Published: 11 April 2020

\begin{abstract}
In recent years, drought disaster has occurred frequently in China, causing significant agricultural losses. It is increasingly important to assess the risk of agricultural drought disaster (ADD) and to develop a targeted risk management approach. In this study, an ADD risk assessment model was established. First, an improved fuzzy analytic hierarchy process based on an accelerated genetic algorithm (AGA-FAHP) was used to build an evaluation indicator system. Then, based on the indicators, the ADD assessment connection numbers were established using the improved connection number method. Finally, the entropy information diffusion method was used to form an ADD risk assessment model. The model was applied to the Huaibei Plain in Anhui Province (China), with the assessment showing that, in the period from 2008 to 2017, the plain was threatened continuously by ADD, especially during 2011-2013. The risk assessment showed that southern cities of the study area were nearly twice as likely to be struck by ADD as northern cities. Meanwhile, the eastern region had a higher frequency of severe and above-grade ADD events (once every 21 years) than the western region (once every 25.3 years). Therefore, Huainan was identified as a high-risk city and Huaibei as a low-risk city, with Suzhou and Bengbu more vulnerable to ADD than Fuyang and Bozhou. Understanding the spatial dynamics of risk in the study area can improve agricultural system resilience by optimizing planting structures and by enhancing irrigation water efficiency. This model could be used to provide support for increasing agricultural drought disaster resilience and risk management efficiency.
\end{abstract}

Keywords: risk assessment; agricultural drought disaster; connection numbers; entropy information diffusion method

\section{Introduction}

At present, drought is a major natural hazard affecting many parts of the world, due to lower levels of rainfall or changing rainfall patterns. The drought development process is gradual and the onset is often difficult to identify [1]. If insufficient precipitation levels continue for a long time, it can result in severe disaster conditions, including a shortage of water sources, deterioration of the ecological environment, and a major worsening in living conditions for many people. Drought is a relatively regional issue, because different regions have specific climatic features. China is a 
typical drought-prone country, and, since 1949, drought has accounted for nearly 35\% of the annual agricultural losses among all natural disasters [2]. In the last decade, China has been frequently and heavily affected by drought disasters [3]. In particular, three large-scale severe droughts struck China from 2009 to 2010, causing considerable social, economic, and ecological losses [4]. As an important defense, risk assessment is an effective way to quantitatively recognize the characteristics of drought disasters. Furthermore, based on the assessment, risk management can be used as a fundamental tool to formulate disaster countermeasures [5], shifting from reactive to proactive management [6].

Drought is generally classified into four categories: meteorological, hydrological, agricultural, and socioeconomic drought [7]. Among them, agricultural drought disaster (ADD) refers to the phenomenon of water deficit in the process of crop growth caused by a lack of water, which ultimately leads to yield reduction and potentially crop death. ADD has already severely restricted the sustainability of agricultural development, especially in terms of food supply security [8]. At present, the perspectives used to assess the risk of ADD include the following: (1) Evaluation models based on the risk index (Group 1). The risk of agricultural drought disaster can be evaluated using the fuzzy comprehensive evaluation method [9]. By constructing an indicator system, the impact of inducing factors can be assessed, such as the disaster risk index (DRI), supported by the United Nations Development Program (UNDP) and the United Nations Environment Program (UNEP) in 2000, which is suitable for preliminary and rapid assessment of disaster risk on a large spatial scale [10,11]. Furthermore, evaluation models are often used to carry out analyses of vulnerability and capacity of a system to insure against ADD [5,12]. (2) Evaluation models based on the process of agricultural drought loss (Group 2). These models reflect the mechanism of ADD by implying a regression relationship between events and the scale of agricultural loss [13]. With the assistance of actual field trials, crop growth models can be used to obtain the risk of agricultural loss, such as the denitrification-decomposition (DNDC) model [14], the erosion productivity impact calculator (EPIC) model [15,16], and the Decision Support System for Agro-Technology transfer (DSSAT) model [17]. (3) Evaluation models based on agricultural loss frequency analysis (Group 3). These models work on the principle that the statistical characteristics of agricultural loss can be reproduced and predicted in the future. They rely on future quantitative forecasts of all kinds of agricultural loss. However, there are some practical problems when insufficient historical disaster data are available and when there are fewer than 30 samples included, resulting in outcomes potentially fluctuating greatly [18].

In summary, Group 1 models can reflect the overall risk of agricultural drought on a large scale with low data requirements. Based on crop growth models, Group 2 models have become an effective and commonly applied research direction. Group 3 models focus on the theories of probability and statistics, although long series of data on agricultural losses are often quite difficult to obtain. Therefore, fuzzy mathematical methods based on information diffusion were introduced to ensure the stability of the evaluation results in Group 3 models $[19,20]$.

This paper provides an ADD risk assessment model based on the improved connection number and entropy information diffusion method. We used the fuzzy analytic hierarchy process based on an accelerated genetic algorithm (AGA-FAHP) to determine the indicators' weight; based on this, we built an evaluation indicator system. Then, the grey correlation coefficient was introduced into the set pair analysis (SPA) method to the obtain connection numbers. In the past, studies often focused on a single affected area, using an inundated area and a crop failure area under agricultural drought as the disaster index in Group 3 models [21,22]; however, we used the connection numbers above. SPA method is a systematic methodology to quantitatively describe the system, proposed by Zhao Keqin in 1989. The core idea is firstly to construct a pair with two relevant sets, and then to calculate the corresponding connection numbers in the integrated system. The connection number can express the proximity between the object and its evaluation criteria. In addition, previous studies were mostly carried out at the regional level, with less original research performed in small unit areas. This study was based on empirical research at the city level for the Huaibei Plain in Anhui Province. 


\section{Study Area}

The Huaibei Plain is in the northern part of Anhui Province, China (from $114^{\circ} 58^{\prime}-118^{\circ} 10^{\prime}$ E to $32^{\circ} 45^{\prime}-34^{\circ} 35^{\prime} \mathrm{N}$ ), between the Yellow River and the Huai River, as shown in Figure 1. The Huaibei Plain is an important part of the North China Plain, with a total land area of $37,400 \mathrm{~km}^{2}$. The study area comprises the cities of Suzhou, Huaibei, Bozhou, Fuyang, Bengbu, and Huainan.

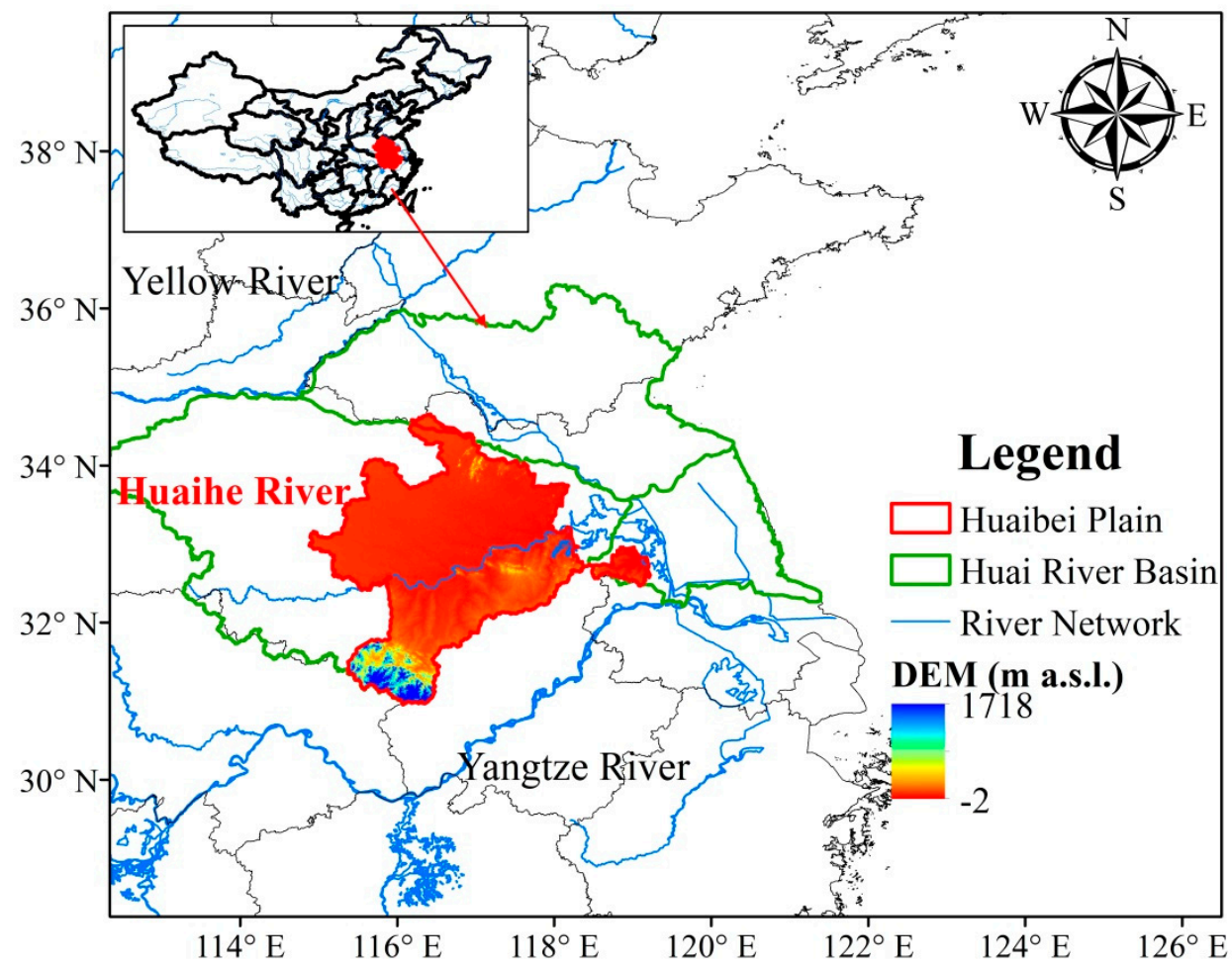

Figure 1. Schematic map of the geographical location and composition of the study area.

The Huaibei Plain is within a warm, temperate, semi-humid monsoon climate zone. The annual average temperature is about $15^{\circ} \mathrm{C}$, and the annual average precipitation is about $890 \mathrm{~mm}$. Controlled by the upper northwest circulation and the subtropical high in the Pacific Ocean, the annual distribution of precipitation in this region is uneven, with frequent droughts and floods. In terms of the multiyear average, the water resources per capita amount to $530 \mathrm{~m}^{3}$ in the study area, accounting for only half of the average level in the province and a quarter of that in China. Corresponding to the relatively scarce water resources, the total value of agricultural production in all six cities in the study area reached 1158.7 billion Chinese yuan (170 billion USD), while the total population working in agriculture in the study area reached about 25 million in 2017 [23-25]. These two agricultural indicators account for about half of the total in Anhui Province, suggesting that the study area is an important region for agricultural production in the province. In addition, according to the available statistics, the central disaster region of agricultural drought in the province is in the Huai River Basin within the study area [23-25].

\section{Methodology}

The risk assessment model was divided into three parts:

1. The ADD evaluation indicator system was built, with the fuzzy analytic hierarchy process based on an accelerated genetic algorithm (AGA-FAHP) method used to determine the weight of each subsystem and indicator.

2. The grey correlation method was used to improve the difference coefficient calculation, which is the foundation for establishing connection numbers. The connection numbers were used to represent 
the agricultural drought disaster index (ADDI), with the spatial and temporal distribution of ADD assessed using the ADDI.

3. The entropy information diffusion method was used to determine the information diffusion coefficient, based on the principle of maximum entropy. Therefore, the risk assessment results could be obtained by estimating the probability distribution of the ADDI.

\subsection{Development of an Evaluation Indicator System}

The evaluation indicator system was divided into four subsystems: the disaster breeding environment, disaster factors, the disaster affected body, and disaster prevention and mitigation measures. These subsystems were further separated into 14 indicators, as shown in Figure 2.

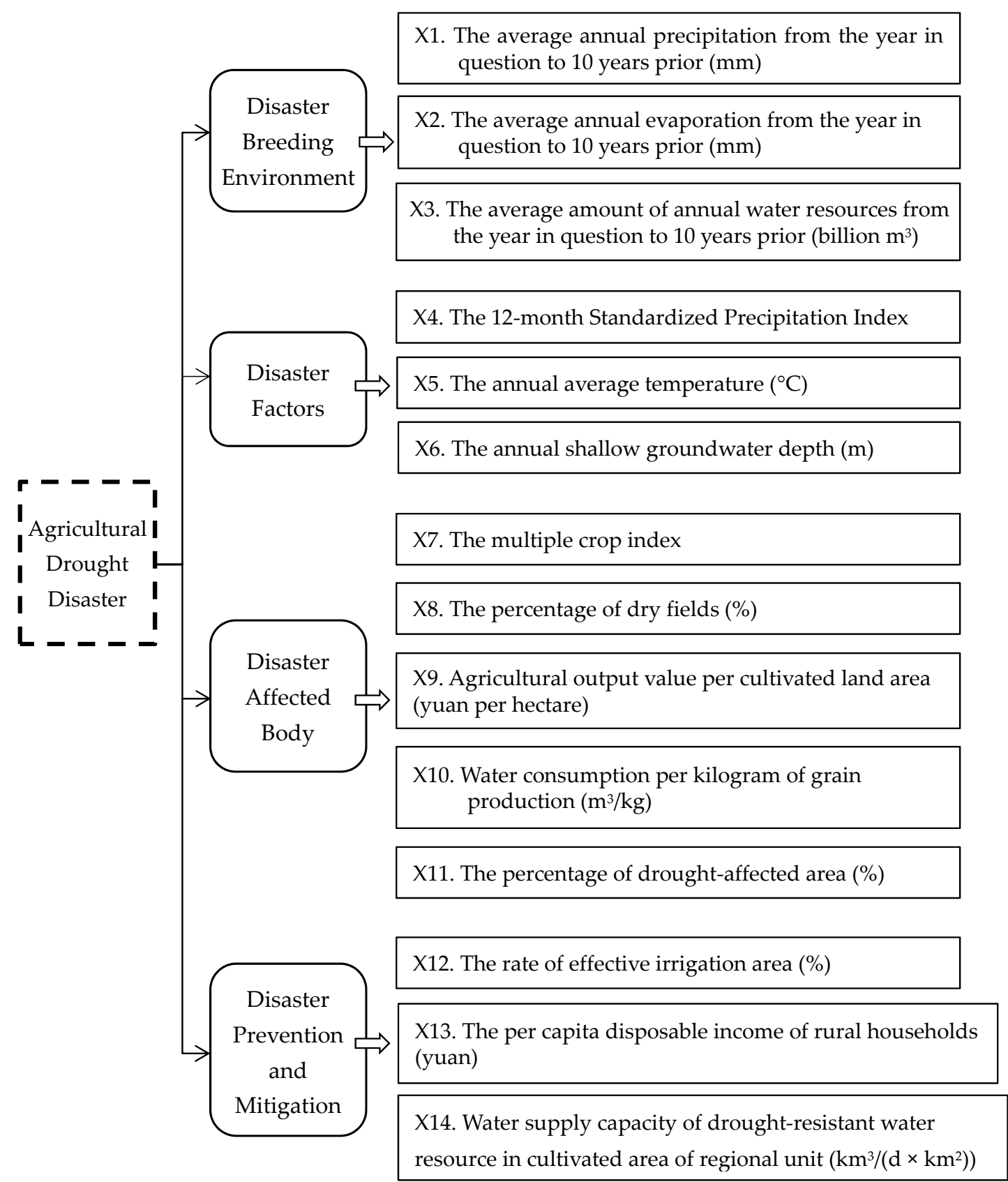

Figure 2. The evaluation indicator system for agricultural drought disaster. 
Using statistical materials [24,25] and information from the National Meteorological Information Center, the Water and Drought Information Network of Anhui Province, and the Meteorological Information Sharing System in the Huai River Basin, the following statistics were collected for each city in the Huaibei Plain, covering the period 2008-2017:

- The disaster breeding environment, including precipitation, evaporation, and amount of water resources. It is the average value from the year in question to 10 years prior.

- The disaster factors, including annual average temperature and shallow groundwater depth. The 12-month Standardized Precipitation Index (SPI) was calculated using monthly rainfall data from 1983 to 2017 provided by the six national weather stations located in the six cities.

- The disaster affected body, including the area of grain planting, cultivated land, dry land, and drought-affected land, along with the value of agricultural production, agricultural water consumption, and total grain output.

- Disaster prevention and mitigation measures, including the area of effective irrigated land, per capita disposable income of rural households, and water supply capacity for drought-resistant water sources.

\subsection{Evaluation Method}

\subsubsection{Determination of the Weight of the Agricultural Drought Evaluation Indicators}

For the subsystem of the evaluation indicator system of ADD, experts were asked to rank the importance of each indicator $\left\{x(k, j) \mid k=1,2,3,4 ; j=1,2, \ldots, n_{k}\right\}$ (where $n_{k}$ is the number of indicators in subsystem $k$ ), adding the importance ranking value to a questionnaire. Smaller ranking values indicate greater importance of the indicator.

Using Equation (1), an average of all experts' rankings of the importance $y(k, j)$ of indicator $j$ in the subsystem was obtained:

$$
y(k, j)=\frac{\sum_{e=1}^{n_{e}} y_{e}(k, j)}{n_{e}}
$$

where $y_{e}(k, j)$ denotes the importance ranking value of one expert for indicator $j$ in subsystem $k(e=1$, $\left.2, \ldots, n_{e}\right)$ and $n_{e}$ is the total number of experts. The fuzzy complementary judgment matrix $A^{k}$ was obtained using Equation (2) [26]:

$$
A^{k}=a(k, j, l), a(k, j, l)=y(k, l) /(y(k, l)+y(k, j))
$$

where $k=1,2,3,4 ; j=1,2, \ldots, n_{k} ;$ and $l=1,2, \ldots, n_{k} ; a(k, j, l)$ indicate the relative importance of indicator $j$ and indicator $l$ in subsystem $k$. The fuzzy complementary judgment matrix $A^{k}$ met the conditions $0 \leq a(k, j, l) \leq 1, a(k, j, l)+a(k, l, j)=1$, and $a(k, j, l)=0.5$, meaning that indicator $j$ was as important as indicator $l$; and $a(k, j, l)>0.5$, meaning that indicator $j$ was more important than indicator $l$.

The improved fuzzy analytic hierarchy process based on an accelerated genetic algorithm (AGA-FAHP) method was used to simultaneously correct the consistency of $A^{k}$ and to calculate the subjective weight of each indicator $\left\{w_{s}(k, j) \mid k=1,2,3,4 ; j=1,2, \ldots, n_{k}\right\}$. If $A^{k}$ met the following condition in Equation (3), it was referred to as the fuzzy consistency judgment matrix [23]:

$$
(a(k, j, m)-0.5)-(a(k, m, l)-0.5)=(a(k, j, l)-0.5)
$$

where $m=1,2, \ldots, n_{k}$. If $A^{k}$ was completely consistent:

$$
\sum_{j=1}^{n_{k}} \sum_{l=1}^{n_{k}}\left|0.5\left(n_{k}-1\right)\left[w_{\mathcal{S}}(k, j)-w_{\mathcal{S}}(k, l)\right]+0.5-a(k, j, l)\right| / n_{k}^{2}=0
$$


where the term to left of the equal sign is the consistency index of $A^{k}[27,28]$. If this value was not greater than a certain threshold, then $A^{k}$ was said to have satisfactory consistency, and, when $A^{k}$ did not have satisfactory consistency, a further matrix correction was required.

As shown in Equation (5), $B^{k}$ refers to the correction matrix of $A^{k}$, and, for simplicity, the weights of $B^{k}$ were still recorded as $\left\{w_{s}(k, j) \mid k=1,2, \ldots, 5 ; j=1,2, \ldots, n_{k}\right\}$, resulting in the minimum fuzzy $B^{k}$ being called the optimal fuzzy consistency judgment matrix of $A^{k}$ [29]:

$$
\begin{aligned}
& \operatorname{minCIC}\left(n_{k}\right)= \frac{\sum_{j=1}^{n_{k}} \sum_{l=1}^{n_{k}}|b(k, j, l)-a(k, j, l)|}{n_{k}^{2}} \\
&+\sum_{j=1}^{n_{k}} \sum_{l=1}^{n_{k}}\left|0.5\left(n_{k}-1\right)\left[w_{s}(k, j)-w_{s}(k, l)\right]+0.5-b(k, j, l)\right| / n_{k}^{2}=0 \\
& \text { s.t. }\left\{\begin{array}{l}
b(k, j, j)=0.5 \\
\sum_{j=1}^{n_{k}} w_{s}(k, j)=1 \\
1-b(k, j, l)=b(k, l, j) \in[a(k, j, l)-d, a(k, j, l)+d] \cap[0,1]
\end{array}\right.
\end{aligned}
$$

where $d$ is a nonnegative parameter, which can be selected from 0 to 0.5 , as required [28]. $\operatorname{CIC}\left(n_{k}\right)$ is the consistency index coefficient, with smaller $\operatorname{CIC}\left(n_{k}\right)$ values indicating a higher degree of consistency. Numerous calculation experiments have been reported $[23,26,29]$, with data indicating that, when the $\operatorname{CIC}\left(n_{k}\right)$ value is less than $0.2, A^{k}$ can be considered to have satisfactory consistency with an acceptable sort weight. Otherwise, it is necessary to adjust parameter $d$ until $A^{k}$ exhibits satisfactory consistency.

\subsubsection{Assessment of Agricultural Drought Disaster}

According to SPA theory, for given sets A and B, it is assumed that there are $S$ features in which two sets are shared, with $P$ features being opposite and $F$ features being uncertain. From this, the connection number between A and B was established, as shown in Equation (6):

$$
\mu_{\mathrm{A}-\mathrm{B}}=S / m+(F / m) \times I+(P / m) \times J
$$

with $S / m=a, F / m$, and $P / m=c$, resulting in Equation (7), where the basic expression of connection numbers is established, as follows [30]:

$$
\mu=a+b I+c J
$$

where $I$ is the discrepant coefficient and $J$ is the opposite coefficient, which is generally equal to -1 . This theory was applied to the assessment of ADD, generating the connection number between assessment samples and grades in a certain region, as shown by Equation (8):

$$
u_{r}(i, g)=a_{r}(i, g)+b_{r}(i, g) I+c_{r}(i, g) J
$$

where $u_{r}(i, g)$ represents the connection numbers between the assessment samples and grades; $i$ is the year $(i=1,2, \ldots, N)$; $g$ is the grade $(g=1,2, \ldots, G)$; and $G=5$ in this study. In addition, smaller $g$ values indicate a smaller degree of $\mathrm{ADD} ; a_{r}(i, g), b_{r}(i, g)$, and $c_{r}(i, g)$ are the connection components; $a_{r}(i, g)$ represents the identity of assessment samples and grade $g$ in year $i ; b_{r}(i, g)$ represents the discrepancy; and $c_{r}(i, g)$ represents the opposition. Then each connection component can be calculated by Equation (9): 


$$
\begin{aligned}
& a_{r}(i, g)=w_{r}(i, g) b_{r}(i, g)=\left\{\begin{array}{l}
w_{r}(i, 2), g=1 \\
w_{r}(i, 1)+w_{r}(i, 3), g=2 \\
w_{r}(i, 2)+w_{r}(i, 4), g=3 \quad c_{r}(i, g) \\
w_{r}(i, 3)+w_{r}(i, 5), g=4 \\
w_{r}(i, 4), g=5
\end{array}\right. \\
& =\left\{\begin{array}{l}
w_{r}(i, 3)+w_{r}(i, 4)+w_{r}(i, 5), g=1 \\
w_{r}(i, 4)+w_{r}(i, 5), g=2 \\
w_{r}(i, 1)+w_{r}(i, 5), g=3 \\
w_{r}(i, 1)+w_{r}(i, 2), g=4 \\
w_{r}(i, 1)+w_{r}(i, 2)+w_{r}(i, 3), g=5
\end{array}\right.
\end{aligned}
$$

where $w_{r}(i, g)$ represents the sum of indicator weights within grade $g$ in year $i$. $\xi_{b a}(i, g)$ is the grey correlation coefficient of $b_{r}(i, g)$ and $a_{r}(i, g)$, with the calculation performed according to Equation (10) [31]:

$$
\xi_{b a}(i, g)=\frac{\Delta_{\min }+\xi \Delta_{\max }}{\Delta_{b a}(i, g)+\xi \Delta_{\max }}
$$

where $\xi(0<\xi<1)$ is the resolution coefficient and $\xi=0.5[32,33] ; \Delta_{b a}(i, g)=\left|b_{r}(i, g)-a_{r}(i, g)\right|, \Delta_{b a}(i, g)$ is the absolute value of difference; $\Delta_{\min }=\min _{i} \min _{g}\left|b_{r}(i, g)-a_{r}(i, g)\right| ;$ and $\Delta_{\max }=\max _{i} \max _{g}\left|b_{r}(i, g)-a_{r}(i, g)\right|$. This resulted in the correlation between $b_{r}(i, g)$ and $a_{r}(i, g)$ being defined as shown in Equation (11):

$$
r_{b a}=\frac{1}{N} \times \frac{1}{G} \sum_{i=1, g=1}^{i=N, g=G} \xi_{b a}(i, g)
$$

where $r_{b a}$ is the average value of all grey correlation coefficients. Similarly, $r_{b c}$ can be calculated by Equations (10) and (11). Here, the difference coefficient $I$ in Equation (8) was calculated using Equation (12) as follows:

$$
I=\frac{r_{b a}}{r_{b a}+r_{b c}}-\frac{r_{b c}}{r_{b a}+r_{b c}}
$$

Equation (12) divides the difference coefficient into two parts. When the difference coefficient is determined by comparing the size of $r_{b a}$ and $r_{b c}$ (if $r_{b a}>r_{b c}$, then $I=r_{b a}$; if $r_{b a}<r_{b c}$, then $I=-r_{b c}$ ), it has the limitation of losing important information when $r_{b a}$ and $r_{b c}$ are close. We allocated the difference coefficient according to their association, which ensured better utilization of the information.

By using the grade eigenvalue method [34] and establishing the connection numbers between assessment samples and grades $u_{r}(i, g)$, the connection numbers for agricultural drought disaster assessment $C N(r, i)$ can be obtained as shown by Equation (13):

$$
C N(r, i)=\sum_{g=1}^{G} \frac{u *_{r}(i, g) \times g}{\sum_{g=1}^{G} u *_{r}(i, g)}
$$

where $u_{r}^{*}(i, g)=0.5+0.5 \times u_{r}(i, g) . C N(r, i)$ was divided into four grades, as shown in Table 1. 
Table 1. Grades of evaluation parameters for agricultural drought disaster assessment.

\begin{tabular}{|c|c|c|c|}
\hline $\begin{array}{l}\text { Evaluation } \\
\text { Indicator }\end{array}$ & $\begin{array}{l}\text { Connection } \\
\text { Numbers }\end{array}$ & $\begin{array}{l}\text { Agricultural Drought } \\
\text { Disaster Index }\end{array}$ & Agricultural Drought Disaster \\
\hline$g$ & $C N(r, i)$ & $s_{i}$ & \\
\hline 1 & {$[0,2.5]$} & {$[0,0.5]$} & No drought \\
\hline 2 & $(2.5,3]$ & $(0.5,0.6]$ & Grade I (mild drought) \\
\hline 3 & $(3,3.5]$ & $(0.6,0.7]$ & Grade II (moderate drought) \\
\hline 4 & $(3.5,4]$ & $(0.7,0.8]$ & Grade III (severe drought) \\
\hline 5 & {$[4,5]$} & {$[0.8,1]$} & Grade IV (extremely severe drought) \\
\hline
\end{tabular}

\subsubsection{Risk Assessment of Agricultural Drought Disaster}

The information diffusion method is a fuzzy mathematical method that compensates for a lack of information, with normal distribution being one of the simplest models in this theory [18]. When supposing that the set of agricultural drought disaster indices is $S=\left\{s_{i} \mid i=1,2, \ldots, N\right\}$, the set of risk assessment domains is $U=\left\{u_{m} \mid m=1,2, \ldots, n\right\} . u_{m}$ is the discrete real value obtained by the dispersion in the interval $[0,1]$. Therefore, $S$ can spread the carried information to all points in $U$ and the corresponding expression is shown in Equation (14) [18,21]:

$$
f_{r}\left(i, u_{m}\right)=\frac{1}{h \sqrt{2 \pi}} \times \exp \left[-\frac{\left(s_{i}-u_{m}\right)^{2}}{2 h^{2}}\right]
$$

where $s_{i}$ is transformed into interval [0,1] by $s_{i}=0.2 \times C N(r, i)$ and $h$ is the information diffusion coefficient, which is generally determined empirically. Hence, in this study it was determined by the principle of maximum entropy, as shown in Equation (15):

$$
\begin{gathered}
\mathrm{H}(x)=-\int_{-\infty}^{+\infty} p(x) \ln p(x) d x \\
\text { s.t. } \int_{-\infty}^{+\infty} p(x) d x=1, \int_{-\infty}^{+\infty} x p(x) d x=\mu, \int_{-\infty}^{+\infty}(x-\mu)^{2} p(x) d x=\sigma^{2}
\end{gathered}
$$

Substituting Lagrange multipliers $\alpha, \beta$, and $\gamma$ into the above equation, $L(p, \alpha, \beta, \gamma)=$ $-\int_{-\infty}^{+\infty} p(x) \ln p(x) d x+\alpha\left(\int_{-\infty}^{+\infty} p(x) d x-1\right)+\beta\left(\int_{-\infty}^{+\infty} x p(x) d x-\mu\right)+\gamma\left(\int_{-\infty}^{+\infty}(x-\mu)^{2} p(x) d x-\sigma^{2}\right.$ and $\frac{\partial L}{\partial p}=-\frac{\partial}{\partial p} \int_{-\infty}^{+\infty} p(x) \ln p(x)-\alpha p(x)-\beta x p(x)-\gamma(x-\mu)^{2} p(x) d x=0$. The first part is a general function of $p(x)$ and $x$, considered as $\frac{\partial}{\partial p}\left[p(x) \ln p(x)-\alpha p(x)-\beta x p(x)-\gamma(x-\mu)^{2} p(x)\right]=0$. This results in $p(x)=C e^{\beta\left(x-\mu+\frac{\alpha}{2 \beta}\right)^{2}}$, where $C(C>0)$ is a constant. Since $p(x)$ is integrable on the domain and symmetric about the axis of the line $x=\mu-\frac{\alpha}{2 \beta}$, it can be established that $\alpha=0$.

According to the constraint shown in Equation (15), $p(x)$ can be established as shown in Equation (16) [35]:

$$
p(x)=\frac{1}{\sigma \sqrt{2 \pi}} \exp \left[-\frac{(x-\mu)^{2}}{2 \sigma^{2}}\right]
$$

However, since $\mu=0$ in this study, the maximum entropy was established as shown in Equation (17):

$$
\begin{aligned}
H(x) & =\int_{-\infty}^{+\infty} p(x) \ln p(x) d x=\int_{-\infty}^{+\infty} \frac{1}{\sigma \sqrt{2 \pi}} e^{-\frac{x^{2}}{2 \sigma^{2}}} \ln \left(\frac{1}{\sigma \sqrt{2 \pi}} e^{-\frac{x^{2}}{2 \sigma^{2}}}\right) d x \\
& =\ln (\sigma \sqrt{2 \pi}) \times \int_{-\infty}^{+\infty} \frac{1}{\sigma \sqrt{2 \pi}} e^{-\frac{x^{2}}{2 \sigma^{2}}} d x+\frac{1}{2 \sigma^{2}} \int_{-\infty}^{+\infty} \frac{x^{2}}{\sigma \sqrt{2 \pi}} e^{-\frac{x^{2}}{2 \sigma^{2}}} d x \\
& =\ln (\sigma \sqrt{2 \pi})+\frac{1}{2}=\ln (\sigma \sqrt{2 \pi e})
\end{aligned}
$$


Substituting Equation (17) into the equation $H(x)=\ln (N)$, it can be established that $\sigma=N / \sqrt{2 \pi e}$. Therefore, the information diffusion coefficient can be calculated as shown in Equation (18) [36]:

$$
h= \begin{cases}\frac{\sigma(b-a)}{N-1}, & N>11 \\ \sigma(b-a), & N \leq 11\end{cases}
$$

where $a$ and $b$ are the maximum and minimum values of the samples in the period, respectively. Substituting Equation (18) into Equation (14), the agricultural drought index sample $f_{r}\left(s_{i}, u_{m}\right)$ is established. The membership function of the corresponding fuzzy subset is established as shown in Equation (19) [18,35]:

$$
f_{r}^{\prime}\left(s_{i}, u_{m}\right)=\frac{f_{r}\left(s_{i}, u_{m}\right)}{\sum_{m=1}^{n} f_{r}\left(s_{i}, u_{m}\right)}
$$

When $f_{r}^{\prime \prime}\left(s_{i}, u_{m}\right)=\sum_{i=1}^{N} f_{r}^{\prime}\left(s_{i}, u_{m}\right)$, the probability of agricultural drought disaster assessment samples falling at $u_{m}$ is established, as shown in Equation (20) [18,35]:

$$
p_{r}\left(u_{m}\right)=\frac{f_{r}^{\prime \prime}\left(s_{i}, u_{m}\right)}{\sum_{m=1}^{n} f_{r}^{\prime \prime}\left(s_{i}, u_{m}\right)}
$$

The probability value of transcending $u_{m}$ can be established using Equation (21), to obtain a better risk assessment result for agricultural drought disaster [18,35]:

$$
P_{r}\left(u_{m}\right)=\sum_{k=1}^{m} p_{r}\left(u_{k}\right)
$$

\section{Results}

\subsection{Weight Analysis of Evaluation Indicators of ADD of the Huaibei Plain in Anhui Province}

Twenty experts were invited to estimate the relative importance of the four subsystems and each indicator based on agricultural development and the actual agricultural droughts that occurred in this region in past years, as shown in Figure 2. The experts were composed of the scholars from universities and scientific research institutes in the field of water resources management and drought prevention and control, as well as government staff in the department of water administration. The five fuzzy complementary judgment matrices were established by combining Equations (1) and (2) to give the following:

$$
\begin{gathered}
A=\left[\begin{array}{llll}
0.50 & 0.75 & 0.75 & 0.60 \\
0.25 & 0.50 & 0.50 & 0.33 \\
0.25 & 0.50 & 0.50 & 0.33 \\
0.40 & 0.67 & 0.67 & 0.50
\end{array}\right] \\
A^{1}=\left[\begin{array}{lll}
0.50 & 0.33 & 0.33 \\
0.67 & 0.50 & 0.50 \\
0.67 & 0.50 & 0.50
\end{array}\right] \quad A^{2}=\left[\begin{array}{lll}
0.50 & 0.50 & 0.33 \\
0.50 & 0.50 & 0.33 \\
0.67 & 0.67 & 0.50
\end{array}\right] \\
A^{3}=\left[\begin{array}{lllll}
0.50 & 0.50 & 0.43 & 0.60 & 0.75 \\
0.50 & 0.50 & 0.43 & 0.60 & 0.75 \\
0.57 & 0.57 & 0.50 & 0.67 & 0.80 \\
0.40 & 0.40 & 0.33 & 0.50 & 0.67 \\
0.25 & 0.25 & 0.20 & 0.33 & 0.50
\end{array}\right] \quad A^{4}=\left[\begin{array}{lll}
0.50 & 0.33 & 0.25 \\
0.67 & 0.50 & 0.40 \\
0.75 & 0.60 & 0.50
\end{array}\right]
\end{gathered}
$$


The element values of the fuzzy complementary judgment matrices above were substituted into Equation (4) as initial values. The weight of each subsystem and its indicators could be obtained as shown in Figure 3. The consistency coefficients of each matrix are 0.004, 0.0035, 0.0014, 0.0109, and 0.0039 , respectively, which meets the condition that the coefficient must be less than 0.2.

Based on the judgment of experts, the weight of the disaster factors subsystem was established as 0.31, which is equal to that of the disaster affected body subsystem. The weight of the disaster prevention and mitigation measures subsystem is 0.23 , and the weight of the disaster breeding environment subsystem is 0.15 . As shown in Figure 3a, X1 is the most important indicator in the subsystem, with annual rainfall being an objective reflection of regional climate characteristics, which can be taken as an important natural background for the formation and development of ADD. In Figure 3b, X4 and X5 can be identified as important indicators in the subsystem. The decrease in rainfall and the increase in temperature in the region can significantly affect the intensity of ADD and the expansion of agricultural drought loss. As shown in Figure 3c, X10 and X11 are important indicators reflecting the level of agricultural production in a region. Agriculture systems are more likely to be affected by drought when they depend on a large amount of water for effective production. X11 reveals the influence on crop growth by identifying the area reduced by more than $10 \%$ compared with to normal yields. As shown in Figure 3d, X12 refers to the area that can be normally irrigated under the conditions of certain water sources and irrigation facilities, which is an important guarantee for food security and agricultural drought resilience.

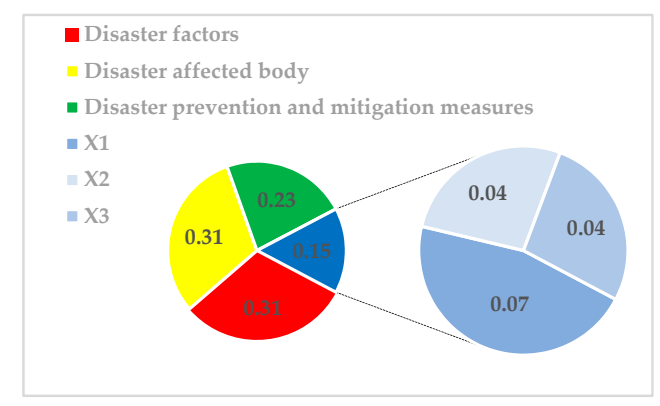

(a)

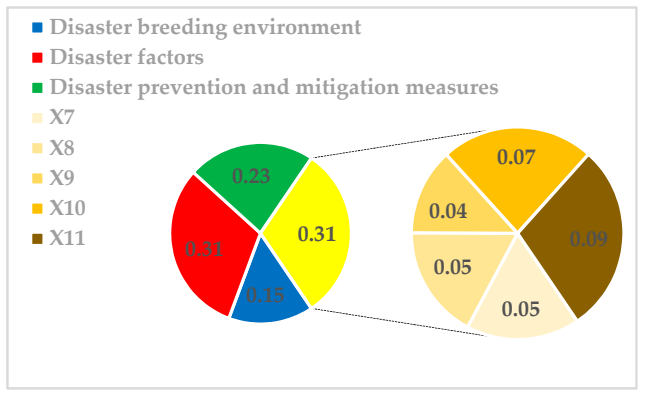

(c)

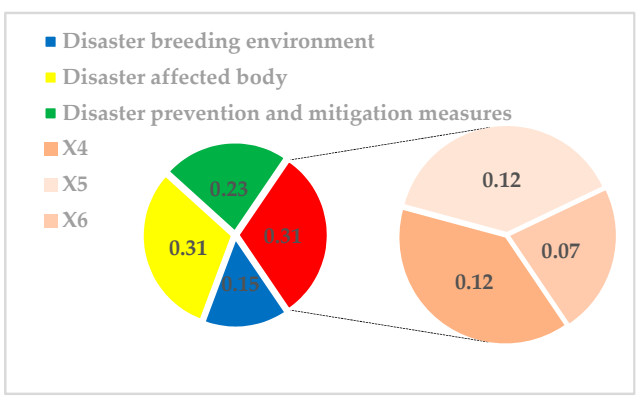

(b)

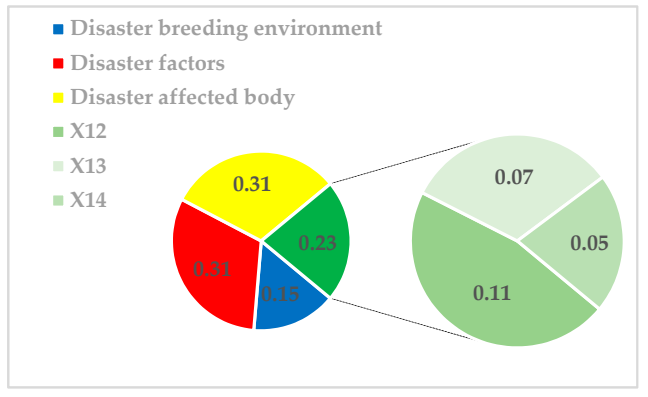

(d)

Figure 3. The four subsystems and each indicator in them for the indicator evaluation system of Huaibei Plain in Anhui Province: (a) disaster breeding environment subsystem; (b) disaster factors subsystem; (c) disaster-affected body subsystem; and (d) disaster prevention and mitigation measures subsystem.

\subsection{Assessment of Agricultural Drought Disaster of the Huaibei Plain}

According to the evaluation indicator system for ADD, as shown in Figure 2, the grey correlation coefficients $\xi_{b a}(i, g)$ and $\xi_{b c}(i, g)$ were obtained by applying the evaluation criteria and the weights of the indicators shown in Figure 3 to Equations (9) and (10). The evaluation indicator criteria were divided by the collected indicator values. Then, using Equations (8), (11), and (12), the connection numbers between the assessment samples and grades $u_{r}(i, g)$ for the Huaibei Plain from 2008 to 2017 
were obtained. The normalized connection numbers $u_{r}^{*}(i, g)$ were calculated and their annual averages are shown in Table 2.

Table 2. Average annual values of the normalized connection numbers $u_{r}^{*}(i, g)$ for Huaibei Plain from 2008 to 2017.

\begin{tabular}{ccccccc}
\hline & Huaibei & Bozhou & Suzhou & Bengbu & Fuyang & Huainan \\
\hline$u^{*}{ }_{r}(i, 1)$ & 0.317 & 0.186 & 0.146 & 0.156 & 0.189 & 0.069 \\
$u^{*}{ }_{r}(i, 2)$ & 0.306 & 0.253 & 0.223 & 0.234 & 0.234 & 0.200 \\
$u^{*}{ }_{r}(i, 3)$ & 0.183 & 0.236 & 0.269 & 0.263 & 0.226 & 0.323 \\
$u^{*}{ }_{r}(i, 4)$ & 0.125 & 0.202 & 0.248 & 0.234 & 0.227 & 0.224 \\
$u^{*}(i, 5)$ & 0.069 & 0.123 & 0.113 & 0.114 & 0.125 & 0.184 \\
\hline
\end{tabular}

As shown in Table 2, larger values indicate a stronger connection between the agricultural drought degree and grade $g$ (Table 1 ) in the corresponding $u_{r}^{*}(i, g)$. The smaller is the value of $g$, the smaller is the degree of agricultural drought disaster; therefore, as shown in Table 2, the highest value in Huaibei was 0.317 and the connection with $g=1$ (no drought). For the other cities, the biggest numbers were those with $g=2$ (mild drought) and $g=3$ (moderate drought) in their corresponding $u_{r}^{*}(i, g)$. These findings illustrate that through the comprehensive analysis of a 10-year dataset, except for Huaibei, the remaining five cities of the Huaibei Plain generally experienced mild to moderate degrees of agricultural drought disaster from 2008 to 2017.

To further assess the ADD status of the Huaibei Plain, the connection numbers $C N(r, i)$ from 2008 to 2017 were obtained, as shown in Figure 4.

As shown in Table 2 and Figure 4, from the perspective of spatial distribution, in the period from 2008 to 2017, the chance of ADD in the southern regions, represented by Fuyang, Huainan, and Bengbu, was obviously more than in the northern regions, represented by Bozhou and Huaibei. Furthermore, the connection numbers in the southern plain were commonly larger than in the north, indicating that the ADD in the southern region was more serious than in the north. In particular, in 2013, it can be clearly seen that a moderate degree of ADD occurred in Fuyang, Huainan, and Bengbu, while the northern region experienced a higher degree of ADD than in previous years, with a lighter ADD status than in the south.

From a temporal perspective, in the period from 2008 to 2017, there were widespread ADD events in the six cities across the Huaibei Plain. The period was roughly divided into three subperiods: (1) From 2008 to 2010. In 2008, the connection numbers of the six cities were relatively small, while, in the following two years, the numbers increased continually and the scope expanded. In 2010, a moderate degree of ADD gradually spread to the whole southern region. (2) From 2011 to 2013. During this stage, ADD was more serious than in the previous period. Although the status in 2011 was somewhat reduced compared to 2010, the occurrence of ADD in the following two years increased rapidly in the southern region. In 2013, Huainan exhibited a severe degree of ADD. (3) From 2014 to 2017. During this stage, the status in the region was alleviated compared to the previous period and the degree of ADD in each city of the Huaibei Plain was mainly mild from 2014 onward. 


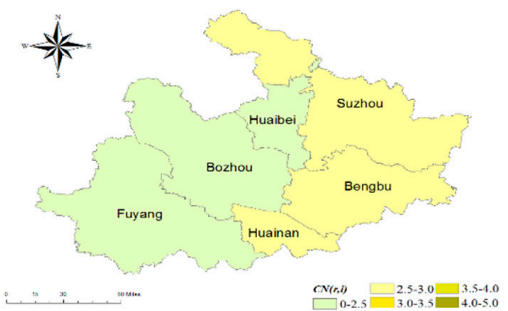

(2008)

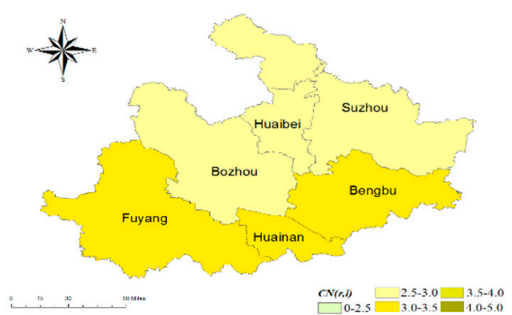

(2010)

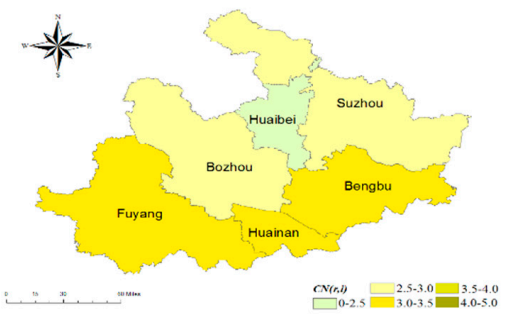

(2012)

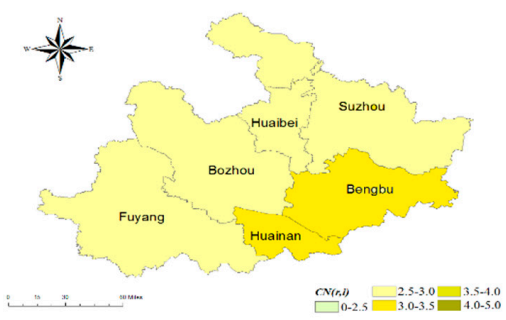

(2014)

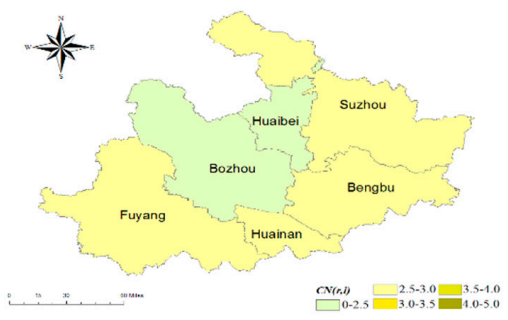

(2016)

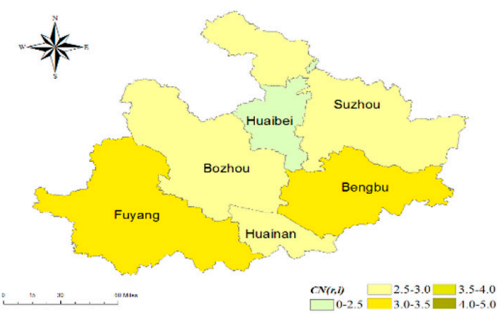

(2009)

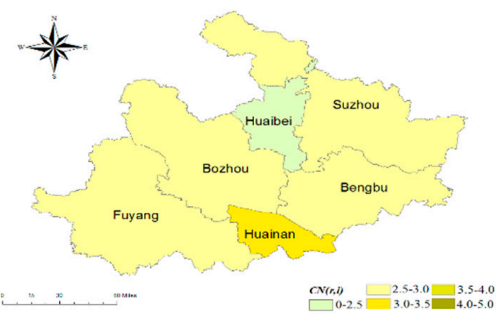

(2011)

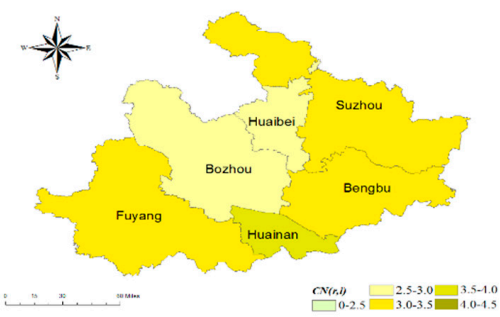

(2013)

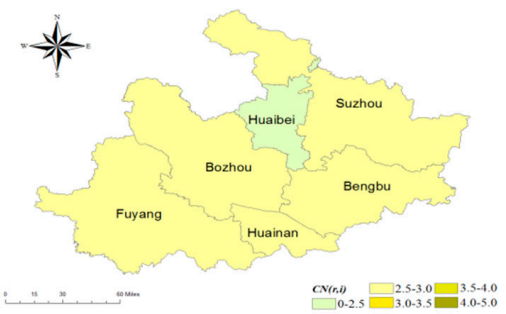

(2015)

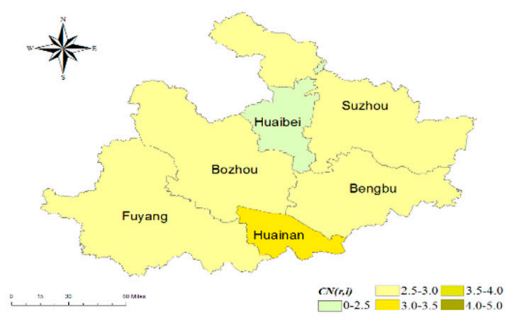

(2017)

Figure 4. Temporal and spatial distribution of connection numbers $C N(r, i)$ for Huaibei Plain.

\subsection{Risk Assessment of Agricultural Drought Disaster for the Huaibei Plain}

Based on the comprehensive assessment of ADD using the $C N(r, i)$ of the Huaibei Plain, the risk of ADD in the region was assessed. Applying the set of risk assessment domains as $U=\left\{u_{m} \mid u_{m}=0.1\right.$, $0.15,0.2,0.25, \ldots, 1\}$ and substituting Equation (18) into Equation (14), the agricultural drought index $f_{r}\left(s_{i}, u_{m}\right)$ values for each city in the plain were obtained.

To visually analyze the spatial distribution and time characteristics of risk across the plain, the probability values $p_{r}\left(u_{m}\right)$ of the agricultural drought disaster index $s_{i}$ fell at $u_{m}$, as calculated by 
Equations (19) and (20). The transcending probability $P_{r}\left(u_{m}\right)$ at $u_{m}$ was obtained using Equation (21). It was found that the ADDI of each city was reduced, generally in the interval of $u_{m} \in[0.5,0.7]$, and therefore the probability value $p_{r}\left(u_{m}\right)$ was refined in the modified interval and the corresponding transcending probability was established. The inverse of transcending probability is the year return, and the year returns of $s_{i}$ at different $u_{m}$ values are shown in Table 3.

Table 3. Year returns of agricultural drought disaster index (ADDI) ( $\left.\mathrm{s}_{i}\right)$ at different values of $u_{m}$.

\begin{tabular}{cccccccccccccc}
\hline \multirow{2}{*}{$\boldsymbol{s}_{\boldsymbol{i}}$} & City & \multicolumn{10}{c}{$\boldsymbol{u}_{\boldsymbol{m}}$} \\
\cline { 3 - 13 } & & $\mathbf{0 . 5}$ & $\mathbf{0 . 5 2}$ & $\mathbf{0 . 5 4}$ & $\mathbf{0 . 5 6}$ & $\mathbf{0 . 5 8}$ & $\mathbf{0 . 6}$ & $\mathbf{0 . 6 2}$ & $\mathbf{0 . 6 4}$ & $\mathbf{0 . 6 6}$ & $\mathbf{0 . 6 8}$ & $\mathbf{0 . 7}$ \\
\hline \multirow{4}{*}{ Year } & Huaibei & $2.8 \mathrm{a}$ & $2.9 \mathrm{a}$ & $2.9 \mathrm{a}$ & $3.2 \mathrm{a}$ & $4.0 \mathrm{a}$ & $5.2 \mathrm{a}$ & $6.4 \mathrm{a}$ & $8.1 \mathrm{a}$ & $14.4 \mathrm{a}$ & $18.5 \mathrm{a}$ & $30.4 \mathrm{a}$ \\
return & Bozhou & $1.8 \mathrm{a}$ & $1.8 \mathrm{a}$ & $1.9 \mathrm{a}$ & $2.1 \mathrm{a}$ & $2.3 \mathrm{a}$ & $2.5 \mathrm{a}$ & $3.4 \mathrm{a}$ & $6.2 \mathrm{a}$ & $12.4 \mathrm{a}$ & $14.7 \mathrm{a}$ & $25.8 \mathrm{a}$ \\
& Suzhou & $1.2 \mathrm{a}$ & $1.3 \mathrm{a}$ & $1.5 \mathrm{a}$ & $1.7 \mathrm{a}$ & $1.9 \mathrm{a}$ & $2.3 \mathrm{a}$ & $2.9 \mathrm{a}$ & $5.1 \mathrm{a}$ & $11.0 \mathrm{a}$ & $13.0 \mathrm{a}$ & $21.3 \mathrm{a}$ \\
& Bengbu & $1.2 \mathrm{a}$ & $1.2 \mathrm{a}$ & $1.4 \mathrm{a}$ & $1.5 \mathrm{a}$ & $1.6 \mathrm{a}$ & $1.9 \mathrm{a}$ & $2.7 \mathrm{a}$ & $4.2 \mathrm{a}$ & $8.2 \mathrm{a}$ & $11.0 \mathrm{a}$ & $20.7 \mathrm{a}$ \\
& Fuyang & $1.4 \mathrm{a}$ & $1.5 \mathrm{a}$ & $1.7 \mathrm{a}$ & $1.9 \mathrm{a}$ & $2.1 \mathrm{a}$ & $2.7 \mathrm{a}$ & $3.6 \mathrm{a}$ & $6.2 \mathrm{a}$ & $12.8 \mathrm{a}$ & $14.5 \mathrm{a}$ & $24.8 \mathrm{a}$ \\
& Huainan & $1.1 \mathrm{a}$ & $1.1 \mathrm{a}$ & $1.1 \mathrm{a}$ & $1.2 \mathrm{a}$ & $1.3 \mathrm{a}$ & $1.5 \mathrm{a}$ & $1.8 \mathrm{a}$ & $2.2 \mathrm{a}$ & $3.8 \mathrm{a}$ & $5.0 \mathrm{a}$ & $9.8 \mathrm{a}$ \\
& Average & $1.6 \mathrm{a}$ & $1.6 \mathrm{a}$ & $1.8 \mathrm{a}$ & $1.9 \mathrm{a}$ & $2.2 \mathrm{a}$ & $2.7 \mathrm{a}$ & $3.5 \mathrm{a}$ & $5.3 \mathrm{a}$ & $10.3 \mathrm{a}$ & $12.8 \mathrm{a}$ & $22.1 \mathrm{a}$ \\
\hline
\end{tabular}

According to the data presented in Table 3, the average frequency of ADDI at $u_{m} \geq 0.5$ in the Huaibei Plain was once every 1.6 years, while the frequency at $u_{m} \geq 0.7$ was once every 22.1 years. This result clearly shows that the impact of ADD, in terms of both frequency and extent, was large. Therefore, ADD was one of the most important natural disasters affecting the Huaibei Plain, highlighting that ADD prevention and control measures are important considerations in natural disaster risk management in the future. The transcending probability $P_{r}\left(u_{m}\right)$ values across the whole interval are shown in Figure 5.
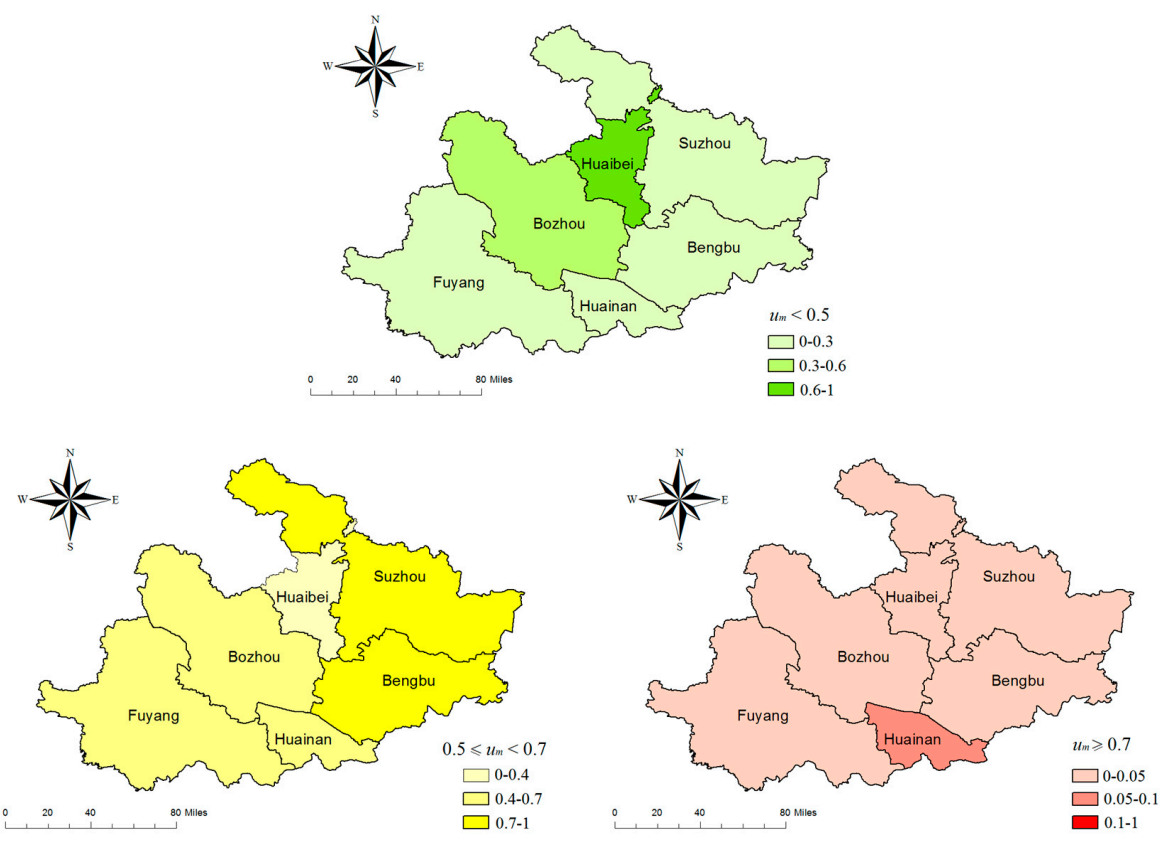

Figure 5. Agricultural drought disaster (ADD) risk assessment maps of the cities of the Huaibei Plain in Anhui Province: (a) when $u_{m} \leq 0.5$; (b) when $0.5<u_{m} \leq 0.7$; and (c) when $u_{m}>0.7$.

Risk refers to the possibility of future adverse events and the losses caused as a result [37]. As shown in Figure 5, the whole interval was divided into three parts: $u_{m} \in[0,0.5], u_{m} \in(0.5,0.7]$, and $u_{m} \in(0.7,1]$. The transcending probability $P_{r}\left(u_{m}\right)$ of $s_{i}$ falls in these three intervals, indicating the different probabilities of ADD occurring to different degrees.

Figure 5a shows that the transcending probability value of $s_{i}$ falls in the range of $u_{m} \in[0,0.5]$, indicating that the risk of ADD events occurring is not high in each city. Figure 5a shows that most areas except Huaibei are light green, which indicates that the area faces a high risk of ADD. Combined 
with Table 3, these findings show that the frequency of ADD at $u_{m}>0.5$ is once every 2.8 years in Huaibei, with the possibility of ADD events every 2-3 years, representing the lowest ADD risk of all of the cities assessed. The average frequency for the southern four cities is once every 1.2 years, which is more frequent than the 2.3 years in Huaibei and Bozhou in the north. In the present study, the southern region was found to be nearly twice as likely to be struck by ADD as the northern region.

Figure $5 \mathrm{~b}$ shows that the transcending probability value of $s_{i}$ falls in the range of $u_{m} \in(0.5,0.7]$, indicating mild and moderate degrees of ADD risk in each city. The probability that Suzhou and Bengbu in the eastern region will experience ADD is higher than that of Fuyang and Bozhou in the western region. Combined with Table 3 , the average frequency of ADD at $u_{m}>0.6$ for Fuyang and Bozhou is once every 2.6 years and at $u_{m}>0.7$ is once every 25.3 years. In contrast, the frequency of ADD at $u_{m}>0.6$ for Suzhou and Bengbu is once every 2.1 years and at $u_{m}>0.7$ is once every 21 years. Based on these findings, the risk of ADD events in Suzhou and Bengbu is higher than in Fuyang and Bozhou.

Figure $5 \mathrm{c}$ shows that the transcending probability value of $s_{i}$ falls in the range of $u_{m} \in(0.7,1]$, indicating the chances of severe ADD in each city. Most parts of the map are light red, indicating lower risk. Combined with Table 3, it can be seen that the probability of severe ADD occurring across the whole Huaibei Plain is relatively small, with an average frequency of 22.3 years. Except for Huainan, which is once every 11 years in the south, the average frequency of ADD at $u_{m}>0.7$ is once every 25 years. Therefore, it is considered that Huainan represents the city at highest risk for ADD on the Huaibei Plain in Anhui Province.

\section{Discussion}

In theory, the drought disaster system is a complex system formed by the interactions of four factors: the disaster breeding environment, disaster factors, the disaster affected body, and disaster prevention and mitigation measures [38]. As a kind of drought disaster, ADD involves the impact of meteorological drought on agriculture [7,39]. The occurrence and severity of ADD depends on the variation of natural factors and the ability of agricultural systems to withstand these changes. The main differences between ADD and other types of drought include aspects of the disaster affected body, as well as the disaster prevention and mitigation measures. The disaster affected body of ADD basically refers to regional agricultural production, as well as to the most direct and far-reaching parts of human society affected by drought. The weights of the four different subsystems in Figure 3 show that the disaster factors and the disaster affected body may be the key factors affecting the spatial and temporal distribution of ADD.

In addition, the disaster prevention and mitigation measures of ADD mainly include economic and social conditions, drought emergence condition, water-saving facilities, and field management. As the most directly affected, rural households are the most important part of the social and economic conditions. Likewise, water supply capacity of drought-resistant water resource is a quantitative index reflecting the efficiency of water resource management. However, when faced with severe drought, the ability of these measures to function effectively would be limited by objective conditions. Therefore, the importance of the disaster prevention and mitigation measures subsystems is slightly less than that of the former two subsystems. In large-scale research, the disaster breeding environment is crucial due to the obvious differences in meteorological environment, geographical conditions, and management policies across the region. However, in small units such as the present study area, the differences between components are not obvious, thus the importance of this subsystem is relatively weak.

Based on the comprehensive assessment in Section 3.2, due to the influence of natural and social factors, a mild to moderate degree of ADD occurred frequently across the Huaibei Plain from 2008 to 2017, with the status being relatively serious in 2013. Since 2014, the impact of ADD in the various cities has reduced. The SPI is a standardized index comparing precipitation over a period of time with the same period in the location's history. It is often used to monitor the severity of drought. We calculated the 12-month SPI of each city using the monthly rainfall history data from 1983 to 2017, obtaining the 
average value in the cities across the Huaibei Plain from 2008 to 2017 (Figure 6). Figure 6 shows that the number of negative SPI values increased from 2009, and only slightly improved until 2015, which shows that the rainfall in the whole Huaibei Plain was less in this period. In particular, from 2011 to 2013 , the SPI value fluctuated from -0.5 to -1 , indicating that the drought was more serious, which is consistent with the comprehensive evaluation results.

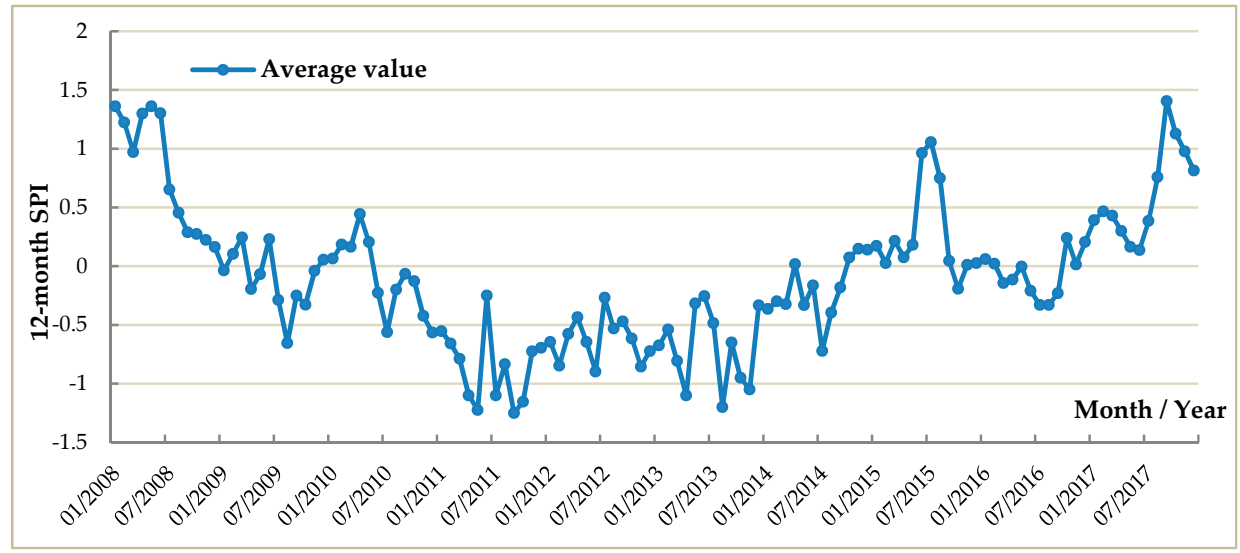

Figure 6. The average value in cities of 12-month Standardized Precipitation Index (SPI) across the Huaibei Plain from 2008 to 2017.

Figure 7 shows that drought-affected areas make up a large part of the cultivated land area, indicating different degrees of ADD occurring in cities across the Huaibei Plain from 2008 to 2017. Combined with the average percentage every year, the results show the relatively largest affected area across the observed period was in 2013, accounting for nearly $35 \%$, while the affected area has decreased since 2014 [24,25]. This finding is consistent with the results of the comprehensive evaluation presented in Section 3.2. According to statistics, there was a rare weather system with high temperatures and low rainfall in southern China in 2013, which lasted for a long duration. The extreme maximum temperature, average temperature, and number of continuous rain-free days on the Huaibei Plain exceeded the averages in previous records for the same period, resulting in the frequent occurrence of ADD in the study area, especially in the summer.

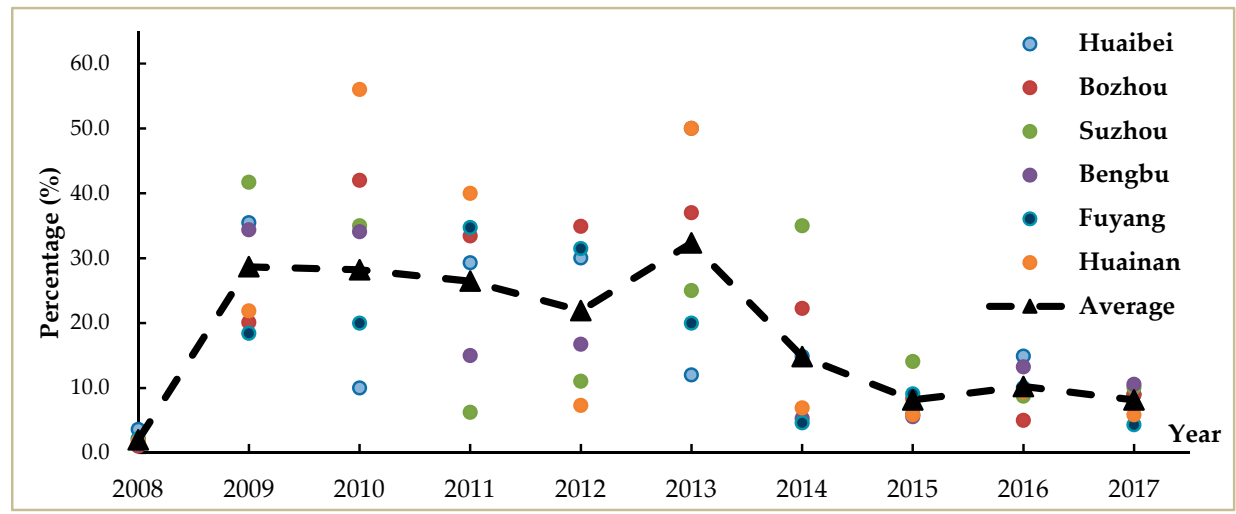

Figure 7. Percentage of drought-affected areas in the cities across the Huaibei Plain from 2008 to 2017.

Based on the risk assessment results of ADD, the cities of the Huaibei Plain, ranked from high to low risk, are: Huainan $>$ Bengbu $>$ Suzhou $>$ Fuyang $>$ Bozhou $>$ Huaibei. The data [24,25] show that the annual temperatures in the southern region are generally higher, especially in Huainan, which is $1.5-2{ }^{\circ} \mathrm{C}$ warmer than the other cities (Figure 8a). At the same time, Huainan and Bengbu have a relatively small percentage of dry fields, with the farmland generally being paddy fields, resulting in highly vulnerable agricultural systems (Figure $8 b$ ). Furthermore, the water consumption per kilogram 
of grain production in Huainan, Bengbu, and Fuyang is about $0.3 \mathrm{~m}^{3} / \mathrm{kg}$, while in Huaibei and Bozhou it is about $0.15 \mathrm{~m}^{3} / \mathrm{kg}$ (Figure $8 \mathrm{c}$ ). This shows that agricultural production in Huaibei and Bozhou has more effective utilization of irrigation water and is less likely to be affected by water shortages. Expect for Huainan and Huaibei, the rate of effective irrigation area of other cities is relatively small (Figure $8 \mathrm{~d}$ ), indicating that the rural water conservancy infrastructure in this area needs to be improved urgently, and the comprehensive agricultural production capacity needs to be improved.
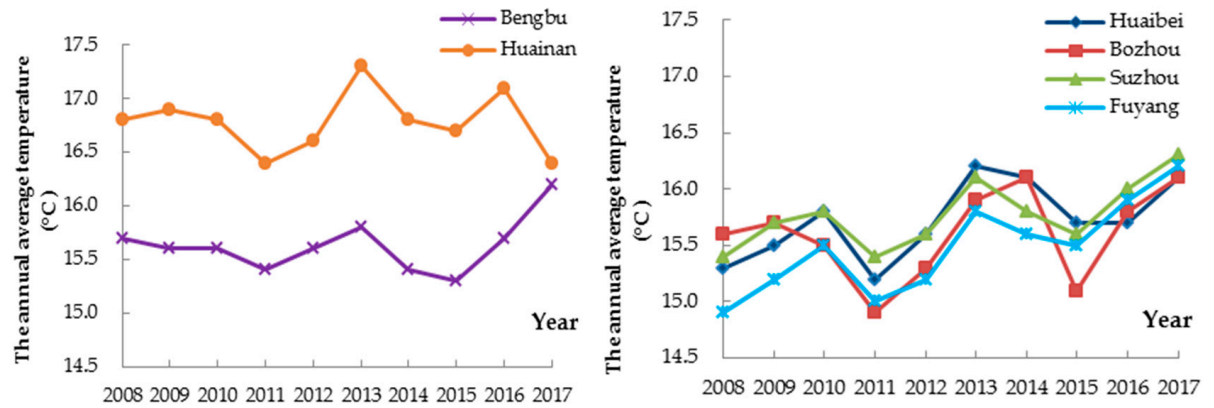

(a) The annual average temperature
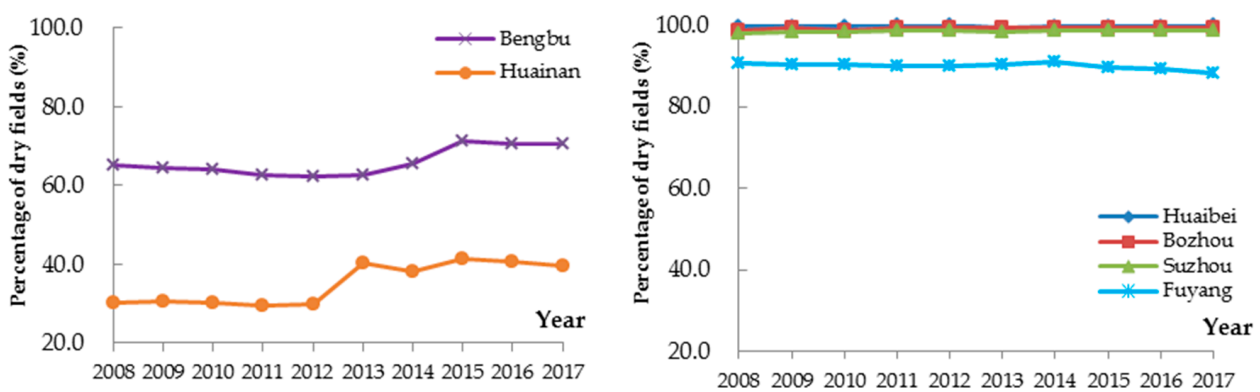

(b) Percentage of dry fields
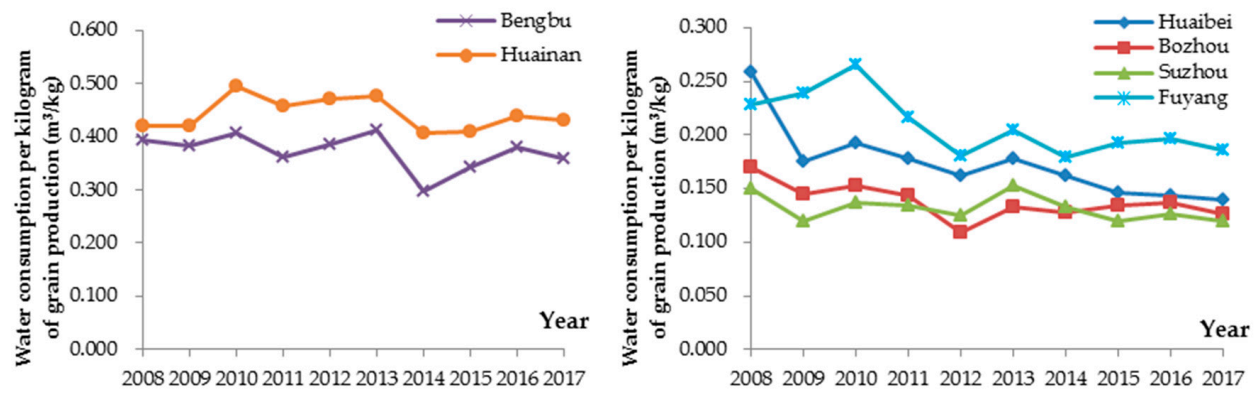

(c) Water consumption per kilogram of grain production
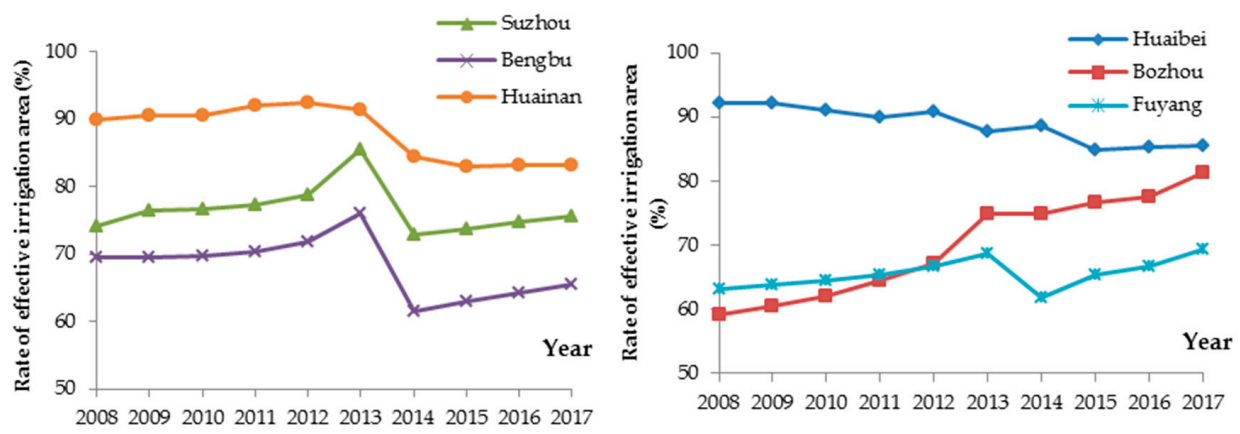

(d) Rate of effective irrigation area

Figure 8. Percentage of drought-affected areas in the cities across the Huaibei Plain from 2008 to 2017. 
Therefore, we suggest that high-risk cities such as Huainan and Bengbu in the study area could improve the resilience of their agricultural systems in the future by optimizing planting structures and enhancing irrigation water efficiency. Increasing drought-tolerant and high-yield crops can realize an increase in production and efficiency. In addition, constructing agricultural water conservancy facilities and providing guidance for farmers on how to apply scientific technology to expand effective irrigation areas would be effective methods to reduce the risk of ADD.

\section{Conclusions}

In this study, a comprehensive agricultural drought disaster index was constructed using the improved connection number method, which not only reflects the loss factor, such as the drought-affected area, but also represents the coincidence of natural and social factors, both temporally and spatially. This was found to be a reasonable and effective method, able to describe the development of ADD accurately. The risk assessment based on entropy information diffusion theory shows the probability of ADD occurring to different degrees. This method conforms to the basic laws of natural disaster risk analysis and provides a scientific basis for proposing targeted risk control recommendations specific to local conditions. The application results for the Huaibei Plain in Anhui Province indicate the following:

1. Using weight analysis, the disaster factors and the disaster affected body were found to be key elements of the agricultural drought disaster system in small units such as the Huaibei Plain. It was also found that the average annual precipitation from the year in question to 10 years prior (X1), 12-month SPI (X4), the annual average temperature (X5), water consumption per kilogram of grain production (X10), percentage of drought-affected area (X11), and rate of effective irrigation area (X12) are more important than other indicators in their corresponding subsystems.

2. Based on a comprehensive analysis of the connection numbers $C N(r, i)$ for the Huaibei Plain from 2008 to 2017, five cities (except Huaibei) had a mild to moderate degree of ADD in the period assessed. The conditions during 2011-2013 were relatively serious, especially in 2013. The chance of ADD in the southern area, represented by Fuyang, Huainan, and Bengbu, was greater than in the northern area, represented by Bozhou and Huaibei. Furthermore, ADD in the southern region was more serious than in the north.

3. The frequency of ADD for each city is mainly once every 1-3 years, and, with an increased agricultural drought disaster index value, the frequency is significantly reduced. The frequency of severe and above-grade ADD is once every 10-30 years. The risk of ADD for the Huaibei Plain is characterized by frequent, mainly mild to moderate risk, making prevention and control measures key for effective risk management of natural disasters in the future.

4. The southern region of the study area was found to be nearly twice as likely to be struck by $\mathrm{ADD}$ as the northern region. Meanwhile, the eastern region has a higher frequency of severe and above-grade events than the western region. The frequency of ADD is once every 2.8 years for Huaibei, which is lower than the average value of the southern four cities. Huainan, in contrast, has a frequency of severe and above-grade ADD of once every 11 years. Based on the risk assessment results above, the cities of the Huaibei Plain were ranked from high to low risk as: Huainan $>$ Bengbu $>$ Suzhou $>$ Fuyang $>$ Bozhou $>$ Huaibei.

5. In this study, some suggestions were proposed for ADD prevention and mitigation based on the analysis of risk assessment results and the background of disaster formation. It is necessary for high-risk cities in the study area, such as Huainan and Bengbu, to improve the resilience of their agricultural systems in the future by optimizing planting structures and enhancing irrigation water efficiency. These results confirm overall that the proposed method is feasible and effective and that the results are reasonable. 
Author Contributions: M.C. and J.J. designed the computations; M.C. and S.N. wrote the paper; Y.C. and C.W. calculated the results; and Y.Z. collected data. All authors have read and agreed to the published version of the manuscript.

Funding: The paper was funded by the National Key Research and Development Program of China under Grant No. 2017YFC1502405, the National Natural Science Foundation of China (Grant Nos. 51579059, 51709071, and 51779067), and the Key Research and Development Program of Shandong Province of China under Grant No. 2017GSF20101.

Conflicts of Interest: The authors declare no conflict of interest.

\section{References}

1. Maybank, J.; Bonsal, B.; Jones, K.; Lawford, R.G.; O’Brien, E.G.; Ripley, E.A.; Wheaton, E. Drought as a natural disaster. Atmos. Ocean 1995, 33, 195-222. [CrossRef]

2. Song, Y.L.; Elisabeth, S.; Chen, D.L.; Dong, W.J. Influence of Climate Change on Winter Wheat Growth in North China during 1950-2000. J. Meteorol. Res. 2005, 19, 501-510. [CrossRef]

3. Ying, G.U.; Jing, N.L.; Jin, L. Analysis on characteristics and situation of drought disasters during past 60 years in China. Water Resour. Hydropower Eng. 2010, 41, 71-74. [CrossRef]

4. Ye, T.; Shi, P.J.; Wang, J.A.; Liu, L.Y.; Fan, Y.D.; Hu, J.F. China's drought disaster risk management: Perspective of severe droughts in 2009-2010. Int. J. Disaster Risk Sci. 2012, 3, 84-97. [CrossRef]

5. Zhang, Q.; Han, L.Y.; Zhang, L.Y.; Wang, J.S. Analysis on the Character and Management Strategy of Drought Disaster and Risk under the Climatic Warming. Adv. Earth Sci. 2014, 29, 80-91.

6. Motha, R.P. Disaster reduction planning and response: The example of national drought policy in USA. Nat. Disasters Extrem. Events Agric. 2005, 179-193. [CrossRef]

7. Mishra, A.K.; Singh, V.P. A review of drought concepts. J. Hydrol. (Amst.) 2010, 391, 202-216. [CrossRef]

8. Liu, L.; Liu, S.; Liu, P. Synthetic analysis and quantitative estimation of the agricultural vulnerability to drought disaster in Hunan province. J. Nat. Disasters 2002, 11, 78-83. [CrossRef]

9. Qu, Y.P.; Gao, H.; Lü, J.; Su, Z.; Cheng, X.; Sun, H. Agricultural drought disaster risk assessment in China based on the regional disaster system theory. J. Hydraul. Eng. 2015, 46, 908-917. [CrossRef]

10. Dalezios, N.R.; Blanta, A.; Spyropoulos, N.V.; Tarquis, A.M. Risk identification of agricultural drought for sustainable Agroecosystems. Nat. Hazards Earth Syst. Sci. 2014, 14, 2435-2448. [CrossRef]

11. He, B.; Wu, J.; Lü, A.; Cui, X.; Zhou, L.; Liu, M.; Zhao, L. Quantitative assessment and spatial characteristic analysis of agricultural drought risk in China. Nat. Hazards 2012, 66, 155-166. [CrossRef]

12. Krishna, V. Risk, vulnerability, and asset-based approach to disaster risk management. Int. J. Sociol. Soc. Policy 2004, 24, 1-48. [CrossRef]

13. Xu, K.; Xu, X.Y.; Li, A.H.; Yang, D.W. Assessing agricultural drought disaster risk in Chengde city using stochastic method. Trans. Chin. Soc. Agric. Eng. 2013, 29, 139-146. [CrossRef]

14. Potopová, V.; Štěpánek, P.; Možný, M.; Türkott, L.; Soukup, J. Performance of the standardised precipitation evapotranspiration index at various lags for agricultural drought risk assessment in the Czech Republic. Agric. For. Meteorol. 2015, 202, 26-38. [CrossRef]

15. Qu, Y.P.; Sun, H.Q.; Su, Z.C. Dynamic assessment of agricultural drought disasters risk based on crop growth model. Agric. Res. Arid Areas 2013, 31, 231-236.

16. Sun, Z.Y.; Zhang, J.Q.; Yan, D.H.; Wu, L.; Guo, E.L. The impact of irrigation water supply rate on agricultural drought disaster risk: A case about maize based on EPIC in Baicheng City, China. Nat. Hazards 2015, 78, 23-40. [CrossRef]

17. Zhao, H.Y.; Gao, G.; Yan, X.D.; Zhang, Q. Risk assessment of agricultural drought using the CERES-Wheat model: A case study of Henan plain, China. Clim. Res. 2011, 50, 247-256. [CrossRef]

18. Huang, C.F.; Liu, X.L.; Zhou, G.X.; Li, X.J. Agricultural natural disaster risk assessment method according to the historic disaster data. J. Nat. Disasters 1998, 7, 1-9.

19. Feng, L.H.; Luo, G.Y. Flood risk analysis based on information diffusion theory. Hum. Ecol. Risk Assess. 2008, 14, 1330-1337. [CrossRef]

20. Liu, J.F.; Li, S.; Wu, J.; Liu, X.J.; Zhang, J.Q. Research of influence of sample size on normal information diffusion based on the Monte Carlo method: Risk assessment for natural disasters. Environ. Earth Sci. 2018, 77, 480. [CrossRef] 
21. Li, M.G.; Zhou, C.S.; Lian, L. Agricultural flood and drought risk Assessment in China based on entropy information diffusion theory. J. Nat. Resour. 2017, 32, 620-631. [CrossRef]

22. Yu, X.B.; Yu, X.R.; Ji, Z.H.; Lu, Y.Q. Risk assessment of typhoon disaster in China's South-East coastal areas-based on information diffusion theory. J. Catastr. 2019, 34, 73-77. [CrossRef]

23. Chen, M.L.; Ning, S.W.; Cui, Y.; Jin, J.L.; Zhou, Y.L.; Wu, C.G. Quantitative Assessment and Diagnosis for Regional Agricultural Drought Resilience Based on Set Pair Analysis and Connection Entropy. Entropy 2019, 21,373. [CrossRef]

24. Anhui Municipal Bureau of Statistics. Anhui Statistical Yearbook, 2009-2018; China Statistics Press: Beijing, China, 2018.

25. Department of Water Resources of Anhui Province. Anhui Water Resources Bulletin, 2008-2017; China Water \& Power Press: Beijing, China, 2017.

26. Cui, Y.; Feng, P.; Jin, J.L.; Liu, L. Water resources carrying capacity evaluation and diagnosis based on set pair analysis and improved the entropy weight method. Entropy 2018, 20, 359. [CrossRef]

27. Lu, Y.J. Weight calculation method of fuzzy analytical hierarchy process. Fuzzy Syst. Math. 2002, 16, 79-85.

28. Song, G.X.; Yang, D.L. Methods for identifying and improving the consistency of fuzzy judgment matrix. Syst. Eng. 2003, 21, 110-116.

29. Jin, J.L.; Wu, K.Y.; Li, R.Z. Region water security evaluation method based on information entropy and improved fuzzy analytic hierarchy process. J. Hydroelectr. Eng. 2007, 26, 61-66.

30. Zhao, K.Q. Set Pair Analysis and its Preliminary Application; Zhejiang Science and Technology Press: Hangzhou, China, 2000; pp. 1-180.

31. Liu, P.J.; Zhao, Z.L.; Yan, X. Grey relational analysis on the effects of rainfall factors on runoff and sediment in the sloping farmland with different plants in the central south of Shandong province. Meteorol. Environ. Res. 2011, 2, 52-55.

32. Kose, E.; Burmaoglu, S.; Kabak, M. Grey relational analysis between energy consumption and economic growth. Grey Syst. Theory Appl. 2013, 3, 291-304. [CrossRef]

33. Yu, H.; Zhang, K. The application of grey relational analysis model in the performance evaluation of agricultural product logistics companies. Appl. Mech. Mater. 2014, 687, 5165-5168. [CrossRef]

34. Jin, J.L.; Fu, J.; Wei, Y.M.; Jiang, S.M.; Zhou, Y.L.; Liu, L.; Wang, Y.Z.; Wu, C.G. Integrated risk assessment method of waterlog disaster in Huaihe River Basin of China. Nat. Hazards 2015, 75, 155-178. [CrossRef]

35. Hao, L.; Zhang, X.; Liu, S. Risk assessment to China's agricultural drought disaster in county unit. Nat. Hazards 2011, 61, 785-801. [CrossRef]

36. Liu, Y.Q.; You, M.; Zhu, J.L.; Wang, F.; Ran, R.P. Integrated risk assessment for agricultural drought and flood disasters based on entropy information diffusion theory in the middle and lower reaches of the Yangtze River, China. Int. J. Disaster Risk Reduct. 2019, 38, 1-14. [CrossRef]

37. Kaplan, S.; Garrick, B.J. On the quantitative definition of risk. Risk Anal. 1981, 1, 11-27. [CrossRef]

38. Jin, J.L.; Li, J.Q.; Zhou, Y.L.; Fei, Z.Y.; Jiang, S.M.; Yuan, X.C.; He, J. Theoretical framework of drought risk assessment. J. Catastr. 2014, 29, 1-10. [CrossRef]

39. He, B.; Wu, J.J.; Lu, A.F. New advances in agricultural drought risk study. Prog. Geogr. 2010, 29, 557-564.

(C) 2020 by the authors. Licensee MDPI, Basel, Switzerland. This article is an open access article distributed under the terms and conditions of the Creative Commons Attribution (CC BY) license (http://creativecommons.org/licenses/by/4.0/). 